\title{
Intra-hisian 2:1 atrioventricular block secondary to Lyme disease
}

\author{
M.-J. Rey, M. Zimmermann, R. Adamec, M. Fleisch, C. Viquerat and J. De Freudenreich \\ Cardiology Center, University Hospital, Geneva, Switzerland
}

\begin{abstract}
KEY WORDS: Intra-hisian atrioventricular block, Lyme disease, ceftriaxone.
We describe a case of Lyme carditis with intra-hisian 2:1 atrioventricular ( $A V$ ) block documented by electrophysiological study. To our knowledge, only two cases of $A V$ block at the level of the His bundle has been described in the literature. Sinus rhythm was restored after 4 days of $i . v$. ceftriaxone.
\end{abstract}

\section{Introduction}

Lyme disease is a tick-borne spirochetal infection, characterized by erythema chronicum migrans and an acute systemic illness. Neurological, cardiac and joint involvement may develop weeks to months later. Some manifestations may last for years or even decades ${ }^{[1]}$. Cardiac disturbances may rarely become permanent ${ }^{[2]}$. Lyme carditis is characterized by various degrees of atrioventricular (AV) block with or without syncope, which usually resolve within a few weeks. The level of block has been described as suprahisian in most cases in whom an electrophysiological study was performed during the acute phase of the illness. In this report, we describe a patient who presented with intra-hisian 2:1 AV block related to Lyme disease.

\section{Case report}

A 49-year-old man complained of sudden discomfort with sweating and unusual shortness of breath occurring during excrcise. No syncope or chest pain was reported. An ECG showed 2:1 second degree AV block, and the patient was admitted to hospital. The patient remembered that 7 weeks earlier he had had arthritis in all the toes of his left foot 2 weeks after a bite by an unidentified insect. He also developed a flu-like syndrome with diffuse myalgia, arthralgia, tiredness, and an erythematous itching rash of the lower left thigh. There was nothing remarkable in his past medical history. On examination, the patient was well with bilateral inguinal lymphadenopathies. His temperature was $37^{\circ} \mathrm{C}$, the pulse was regular at 60 beats per minute and blood pressure was $140 / 80 \mathrm{mmHg}$. A protosystolic murmur was heard at the left sternal border. Pulmonary auscultation was normal. Liver and spleen were of normal size. There was oedema of the left ankle; the left toes were warm and pain was elicited by pressure over the foot. Neurological examination was normal. Erythrocyte sedimentation rate was $22 \mathrm{~mm}$ per hour, haemoglobin $13 \cdot 7 \%$, white blood cells count $6100 . \mathrm{mm}^{-3}$.

Submitted for publication on 13 August 1990, and in revised form 29 October 1990.

Correspondence: Marc Zimmermann, MD, Cardiology Center, Unjversity Hospital, 24 rue Micheli-du-Crest, 1211 Geneva 4, Switzerland.
An electrocardiogram showed sinus rhythm at a rate of $80 \mathrm{~min}^{-1}$ and 2:1 second degree AV block (Fig. 1).

An exercise stress test showed persistent 2:1 AV block with a normal increase in sinus rate to 140 beats. $\mathrm{min}^{-1}$ at $125 \mathrm{~W}$ (Fig. 2). Echocardiography was normal. An electrophysiological study was performed 4 days after the beginning of symptoms: it showed two hisian potentials, $\mathrm{H}_{1}$ and $\mathrm{H}_{2}$, but these were never recorded in sequence. However, on the tracing showing 2:1 block, the $\mathrm{H}_{1}$ potential appeared every time after a blocked $\mathrm{P}$ wave; the $\mathrm{A}-\mathrm{H}_{1}$ interval was $130 \mathrm{~ms}$. The $\mathrm{H}_{2}$ potential was recorded only in the case of $\mathrm{AV}$ conduction. The $\mathrm{A}-\mathrm{H}_{2}$ interval was $160 \mathrm{~ms}$ and the $\mathrm{H}-\mathrm{V}$ interval $50 \mathrm{~ms}$ on conducted beat (Fig. 3). Although the His potential was difficult to visualize, the sequence suggesting intra-hisian block was highly reproducible with constant $\mathrm{A}-\mathrm{H}_{1}$ and $\mathrm{A}-\mathrm{H}_{2}$ intervals (Fig. 4). Atrial pacing rapidly aggravated the degree of $\mathrm{AV}$ block ( 3 to 1,4 to 1 ) and atropine did not restore $1: 1$ AV conduction. No other electrophysiological abnormalities were observed and a temporary pacemaker was inserted. Ceftriaxone ( $2 \mathrm{~g}$ per day i.v.) was administered for 15 days together with only one oral dose of prednisone $50 \mathrm{mg}$. Lyme disease was confirmed by serology, showing positive borrelia burgdorferi IgG (titre: 1/64) and positive borrelia burgdorferi IgM antibodies. The clinical course was uneventful: normal AV conduction resumed after 4 days of treatment and the pacemaker was removed. At follow-up, five months later, the patient was asymptomatic; the physical examination, the 12 lead ECG and a Holter recording were all normal.

\section{Discussion}

Carditis occurs in 4 to $12 \%$ of cases of Lyme disease, usually at a mean of 4.8 weeks (range 4 days to 7 months) after the initial disease ${ }^{[1]}$. Varying degrees of AV block are the commonest manifestations of Lyme carditis ${ }^{[2,3]}$ : from 56 reported cases, $49(87.5 \%)$ had documented AV block; in 32 cases complete or high-grade AV block was observed, usually with syncope. The escape rhythm rarely had a wide QRS pattern (11 cases) or a rate below 40 beats . $\min ^{-1}$ (10 cases). Fluctuating or intermittent left or right bundle branch block has also been observed $d^{[2,4-6]}$. 


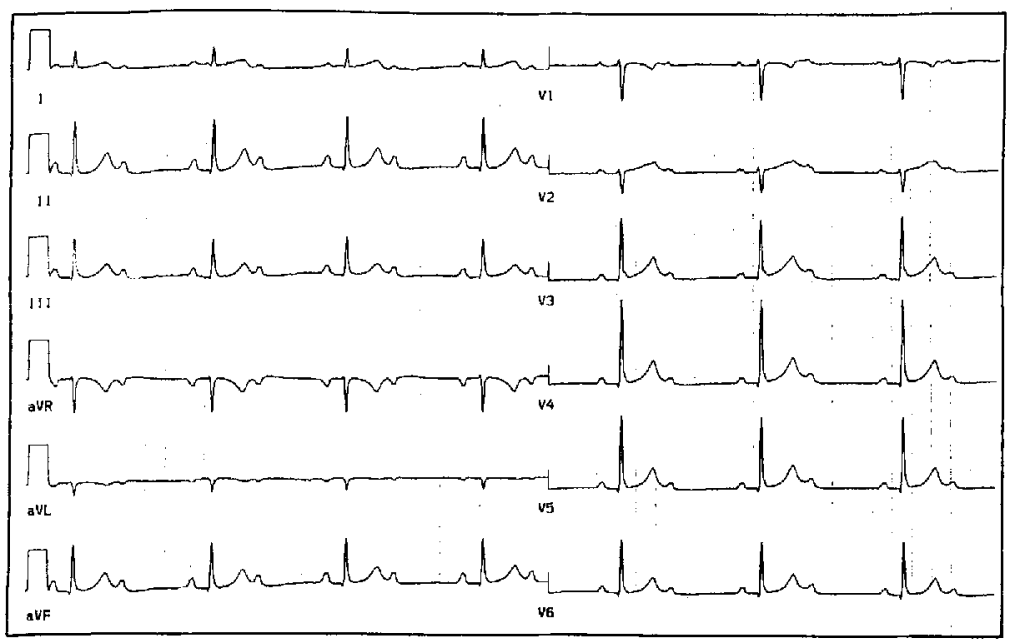

Figure 1 Resting 12-lead electrocardiogram showing 2:1 AV block (atrial rate 80 beats. $\mathrm{min}^{-1}$, ventricular rate 40 beats. $\mathrm{min}^{-1}$ ).

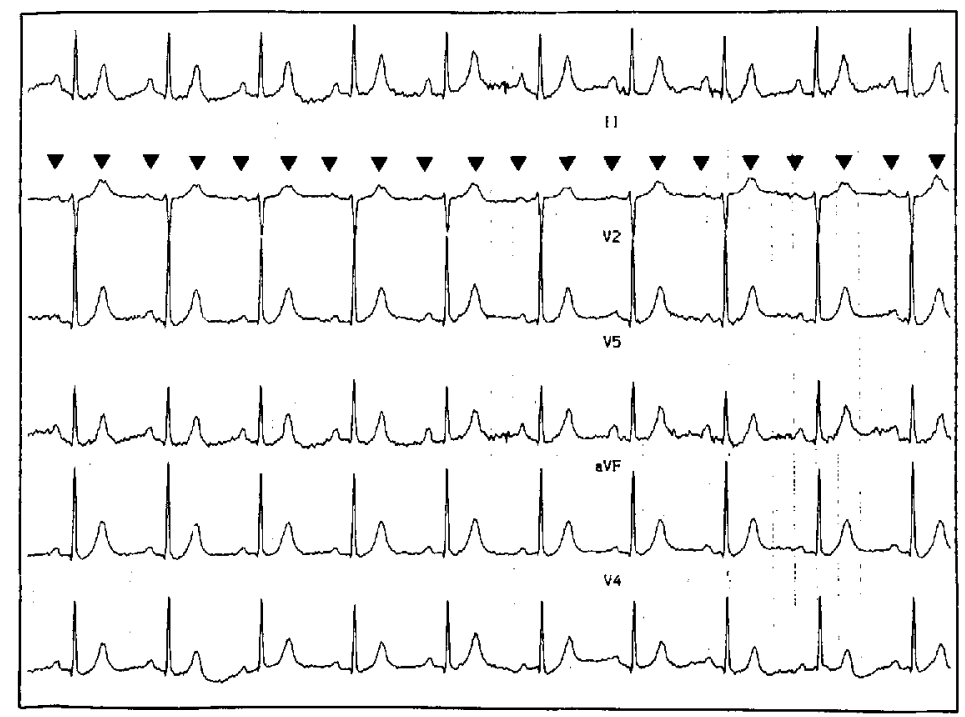

Figure 2 Exercise electrocardiogram showing persistant 2:1 AV block with an atrial rate of 140 beats . $\min ^{-1}$ (arrows) and a ventricular rate of 70 beats . min ${ }^{-1}$.

Several reports have mentioned transient lack of any escape rhythm, with asystole of 4 to 9 seconds ${ }^{[2,4,5,7-9]}$. An electrophysiological study was performed in only 12 patients with Lyme carditis during the acute or subacute phase of the disease (Table 1); in the majority of cases (10/12), the level of AV block was considered to be above the bundle of His. Intra or infra-hisian block has been only rarely suspected or documented ${ }^{[2,3,7]}$. Van der Linde et al..$^{[2]}$ reported a case where the electrophysiological study showed a small positive His bundle deflection without a negative deflection at all sites mapped in the His bundle region. The $\mathrm{AH}$ interval was normal, but there was no relation between His bundle activity and QRS complexes. In the case reported by McAlister et al. ${ }^{[3]}$, a prolonged $\mathrm{HV}$ interval $(70 \mathrm{~ms})$ suggested an infra-hisian conduction delay. In the case published by Cornuau et $a l^{[7]}$, the electrophysiological study showed a normal
$\mathrm{AH}$ interval ( $80 \mathrm{~ms})$, major intra-hisian conduction delay $\left(\mathrm{H}_{1}-\mathrm{H}_{2} \quad 120 \mathrm{~ms}\right)$ and infra-hisian block. The recording published by Dunica et al.$^{[9]}$ suggested supra-hisian block with an AH interval of $175 \mathrm{~ms}$ and an HV interval of $45 \mathrm{~ms}$; however the author suspected that the block could have also been present at a lower level because there was a small atrial deflection on the AV lead during the AV block and because no escape rhythm was present during complete AV block. Kapusta et al..$^{[10]}$ also observed a small deflection after the first blocked $A$ wave, which could be interpreted as a partial activity of the His bundle. Our patient had an electrophysiological study performed 4 days after the onset of cardiovascular symptoms, which showed intra-hisian AV block; although the double His potential was difficult to visualize, the sequence suggesting intra-hisian block was highly reproducible. All groups have reported that patients with AV block have an 


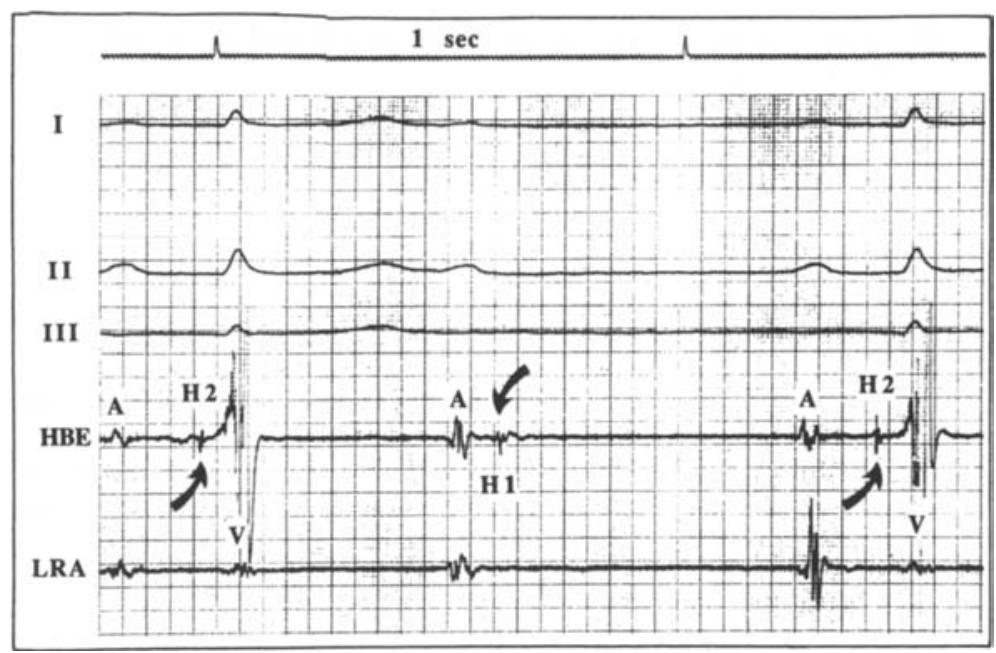

Figure 3 A 2:1 AV block arising with the His bundle: during sinus rhythm, two $\mathbf{H}$ potentials (arrows) are identified $\left(\mathrm{H}_{1}\right.$ and $\left.\mathrm{H}_{2}\right)$ and the block occurs between the two $\mathrm{H}$ deflections. HBE: His bundle recording; LRA: low right atrium; A: atrium; V: ventricle.

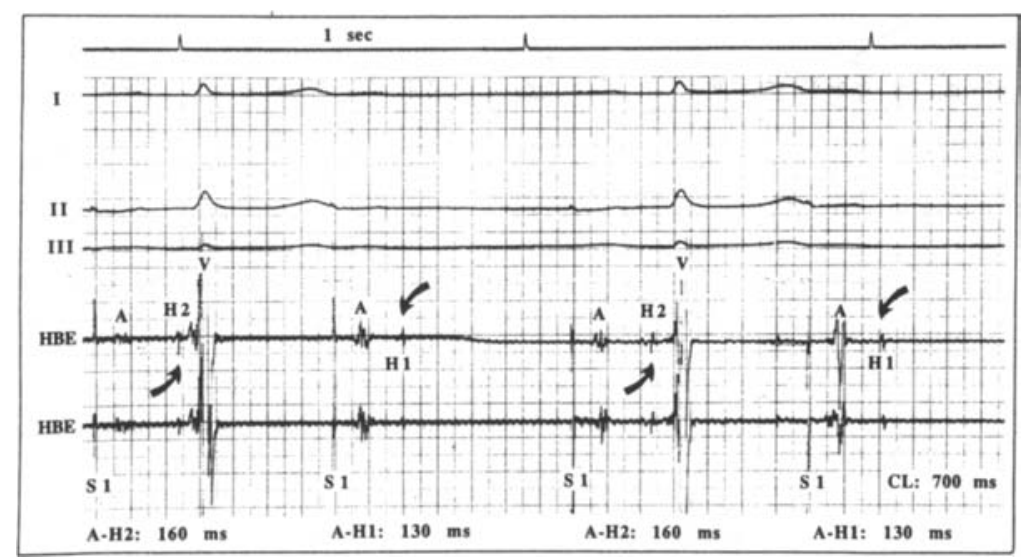

Figure 4 A 2:1 AV block occurring within the His bundle during atrial pacing at a cycle length of $700 \mathrm{~ms}$. Abbreviations same as Fig. 3.

Table 1 Electrophysiological data obtained during the acute or subacute phase of Lyme carditis: review of the literature

\begin{tabular}{|c|c|c|c|c|}
\hline First author & n & $\mathrm{ECG}$ & Level of block & Evolution \\
\hline Van der Linde $\mathrm{e}^{[2]}$ & 1 & $\begin{array}{l}\text { complete AV block } \\
\text { complete AV block }\end{array}$ & intra-hisian & permanent PM \\
\hline & & + LBBB, junct. escape & supra-hisian & SR \\
\hline McAlister ${ }^{[3]}$ & 2 & high grade AV block & supra-hisian & SR \\
\hline Cornuaud'] & 1 & complete AV block & intra-hisian & SR \\
\hline Reznick $^{[8]}$ & 1 & 2:1 AV block & supra-hisian & SR \\
\hline Dunika ${ }^{[9]}$ & 1 & $\begin{array}{c}\text { 2:1 AV block } \\
\text { complete AV block } \\
\text { incomplete RBBB }\end{array}$ & supra-hisian & SR \\
\hline Kapusta ${ }^{[10]}$ & 2 & 2-3:1 AV block, RBBB & $\begin{array}{l}\text { supra-hisian } \\
\text { intra-hisian? }\end{array}$ & SR \\
\hline Steere ${ }^{[1]}$ & 1 & complete AV block & supra-hisian & SR \\
\hline Lavaud ${ }^{[14]^{\circ}}$ & 1 & complete AV bloc & supra-hisian & SR \\
\hline Rey & t & 2:1 AV block & intra-hisian & SR \\
\hline
\end{tabular}

$\mathrm{AV}=$ atrioventricular; $\mathrm{SR}=$ sinus rhythm; LBBB = left bundle branch block; $\mathrm{n}=$ number of cases; $\mathrm{RBBB}=$ right bundle branch block; $\mathrm{PM}=$ pacemaker. 
excellent prognosis: most cases resolved within 1 to 2 weeks, and three within 6 weeks ${ }^{[3]}$. Only Van der Linde et $a l^{[2]}$ reported a case who required implantation of a permanent pacemaker after 15 weeks of follow-up. Therefore, the insertion of a permanent pacemaker is rarely indicated. Lyme carditis may occur with highdegree AV block during the sub-acute phase of infection: this was the case for our patient who had the first symptoms of erythema in August 1989, 7 weeks before the cardiovascular manifestations of the disease.

Several therapeutic principles of Lyme carditis are generally accepted: hospitalization and continuous monitoring are advisable for patients with second-degree or complete AV block, and with first-degree AV block if the PR interval exceeds $0.30 \mathrm{~s}^{[1]}$. At the present time either intravenous penicillin $\mathrm{G} 20$ millions units per day or oral tetracycline for 10 to 20 days are recommended; in high degree $\mathrm{AV}$ block, ceftriazone $2 \mathrm{~g}$ intravenously once a day for 14 days can be prescribed instead of penicillin ${ }^{[1,12]}$. It seems that the persistence of the spirochetes within the myocardium is an intrinsic part of the pathophysiology of Lyme carditis. The observation of spirochetes within cardiac tissue ${ }^{[9,13]}$ lends further support to this hypothesis. It remains unclear, however, whether continued disease activity requires the persistence of live spirochetes or whether it results primarily from immune-mediated mechanisms.

In our case, the administration of ceftriazone resulted in rapid restoration of normal AV conduction without any sequellae.

\section{References}

[1] Steere AC. Lyme disease. N Engl J Med 1989; 321: 586-96.
[2] Van der Linde MR, Crijns HJGM, de Koning J Range of atrioventricular conduction disturbances in Lyme borreliosis: a report of four cases and review of other published reports. Brit Heart J 1990; 63: 162-8.

[3] McAlister HG, Klementowicz PT, Andrews C, Fischer JD, Feld M, Furman S. Lyme carditis: an important cause of reversible block. Ann Intern Med 1989; 110: 339-45.

[4] Viereys C, Allal J, Coisne D, Thomas Ph, Neau JP, Breux JP. Aspects européens de la maladie de Lyme. Presse Med 1987; 16: $59-62$.

[5] Allal J, Coisne D, Thomas P, et al. Manifestations cardiaques de la maladie de Lyme. Ann Med Interne (Paris) 1986; 137 : $372-4$.

[6] Alpert LI, Welsch P, Fischer N. Gallium-positive Lyme disease myocarditis, Clin Nucl Med 1985; 10:617.

[7] Cornuau C, Bernard M, Daumas P, Oblet B, Poirot G, Valois $M$. Les manifestations cardiaques de la maladie de Lyme: à propos de 2 observations. Ann Cardiol Angeiol 1984; 33: 395-9.

[8] Reznick JW, Braunstein DB, Walsch RL et al. Lyme carditis. Electrophysiologic and histopathologic study. Am J Med 1986; 81: $923-7$.

[9] Dunica S, Piette JC, Nassar N, Beaufils P. Une nouvelle cause de bloc auriculo-ventriculaire aigu transitoire: la maladie de Lyme. Arch Mal Coeur 1986; 79: 1251-5.

[10] Kapusta P, Fauchier JP, Cosnay R, Huguet R, Grézard O, Rouesnel $P$. Troubles conductifs sino-auriculaires et auriculoventriculaires de la maladie de Lyme. Arch Mal Coeur 1986; 9 : 1361-6.

[11] Steere AC, Batsford WP, Weinburg M, et al. Lyme carditis: cardiac abnormalities of Lyme disease. Ann Intern Med 1980; 93: 8-16.

[12] Dattwyler RJ, Halperin JJ, Pass H, Luft BJ. Ceftriaxone as effective therapy in refractory Lyme disease. J Infect Dis 1987; 155: $1322-5$.

[13] Stanek G, Jutta K, Bittner R, Glogar D. Isolation of Borrelia Burgdorferi from the myocardium of a patient with longstanding cardiomyopathy. N Engl J Med 1990; 322: 249-52.

[14] Lavaud P, Etienne J, Chamot E et al. Bloc auriculo-ventriculaire aigu associé à une maladie de Lyme. Presse Med 1985; 14 : 2020 . 